\title{
USE OF COLOURING MATTERS IN FOODS
}

$\mathrm{T}$ HE addition of colour to food is common practice; but many colouring substances are toxic and some have already been prohibited. The main issue before the Food Standards Committee set up by the Ministry of Food* was whether the public health would best be safeguarded by extending the present list of prohibited colours or by introducing a list of permitted colours. At first it considered recommending the adoption of the list approved in the United States and Canada; but representation was made to it that "this list would be insufficient to meet the present needs of the food industry in this country". The United States list contains nineteen colours ; the colours in use in Britain at the present time number seventy-nine.

The Committee came to the conclusion that "the present Regulations under which in practice almost all known synthetic colours cen be used in foods are unsatisfactory", and it states that "a review of scientific literature reveals that for only comparatively few colours is there information as to chronic toxicity or carcinogenicity". It is disturbing to note that, out of the list of seventy-nine colours at present in actual use, the Committee found it necessery to recommend the rejection of thirty-five "because examination of the experimental evidence shows that they have definitely harmful effects on health, or that their chemical structure includes groupings likely to be set free in the body which have been shown to cause cancer or other harmful effects in animals or man". Only twelve out of the seventynine seemed definitely safe, the remaining thirty-two being colours "about which there was no direct

* Ministry of Food. Food Standards Committee Report on Colouring Matters : Recommendations relating to the Use of Colouring Matter in Foods. Pp. 27. (London : H.M.S.O., 1954.) 18. net. evidence of toxicity or harmfulness" but about which there was equally room for doubt.

The Committee states that it has not been able to meet in full the stated requirements of the trade; but there is no doubt that it has gone as far as it could without subjecting the public to quite unnecessary risks, and it includes a recommendation that provision be made for additions to or deletions from the list as further information becomes available.

In view of the widespread use of colourings, it is perhaps not surprising that the Committee should so readily accept the need to continue to permit the use of at least some; but from a nutritional point of view there is much to be said against the practice, quite apart from any danger of toxicity. One can agree with the Committee that "it is generally accepted to be physiologically sound that food should be presented in as attractive a form as possible" and perhaps also that "without the addition of colour many foods would have a drab unattractive appearance". It should, however, be stressed that a drab unattractive appearance indicates a poor standard of catering and is commonly produced by methods of cooking which greatly lower the nutritive value of the food being cooked. If, for example, fish looks drab, let it be served with tomatoes or a naturally green vegetable; these will greatly add to the nutritive value of the meal, whereas dyeing the fish will not. Processing and cooking methods which give a high nutritive value to the food do not require the addition of dyestuffs to make the products attractive. It is necessary to emphasize, far more than the Committee has done, that colourings can be used "to mask the use of inferior ingredients and to give a false impression of quality". M. W. Grant

\section{SECOND INTERNATIONAL CONGRESS OF FILMOLOGY, PARIS}

$I^{1}$ has been found necessary to coin a word to distinguish the study of the film in all its aspects from more limited forms of film study - such as study from the æesthetic angle or study directed towards film-making. Like 'musicology', the term 'filmology' seems to have become established. The Institut de Filmologie, under the double sponsorship of the Faculty of Letters and the Faculty of Science, was founded in the University of Paris in 1948. A course in filmology is provided, and a diploma granted for this subject.

The Second International Congress of Filmology was held in the University of Paris during February 19-23, under the presidency of $M$. Mario Roques. The executive delegate was M. G. Cohen-Séat (who is the director of the Institut de Filmologie), and the convener was Dr. W. D. Wall, of the Department of Education, Unesco; the presidents of the two Congress Sections were Prof. A. Michotte van den Berck, of the University of Louvain (unfortunately prevented from attending owing to ill-health), and Prof. H. Laugier, of the Sorbonne. Of the three hundred and thirty participents representing twentysix countries, eight were from Great Britain, and two of these-Miss G. Keir and Prof. G. P. Meredith- presided over Congress sessions. The work of the Congress was at first carried out by seven groups, acting independently; then followed sessions of combinations of these groups, and, finally, all the group members came together to take part in symposia.

Group 1 of the Congress dealt with psychophysiological effects of cinematograph projection. Problems of three-dimensional and of colour representation, and of sound-recording, were considered, as well as physiological effects and a number of isolated perceptual phenomena; attention was also paid to the electro-encephalograph in relation to the film. Among those contributing were J. Faure, Y. Gallifret, C. E. M. Hansel, G. Heuyer and S. Lebovici. Prof. M. J. Colle, who presided, pointed out that some of the effects of the stimulation of films can be studied by normal physiological procedure, for they are the result of innate reactions. But another and more important category of effects are those resulting from an interpretation of the stimuli, and are partly dependent on acquired experience. These latter effects can best be investigated by the methods of the psychologist.

The psychological approach was employed by Group 2 in its study of the reactions of cinema 
audiences. Sociological problems of the cinema were examined by Group 3 : the 'stereotypes' of the popular film, the intentional and unintentional propaganda of films, and the possibility of collecting material to provide a statistical basis for further sociological research. Group 4 dealt with the film as an instrument of teaching and research. Group 5 considered laws in relation to the cinema, the classifying of films according to their possible effects on viewers, and problems of censorship. Comparison of the film with other forms of expression was carried out by Group 6, and specifically with the medium of television by Group 7. The presidents of these six groups were M. Ponzo, M. J. Flaud, F. Buytendijk, G. Calo, B. Knipping and A. Marzi, and the chairmen at their various sessions were M. P. Fraisse, G. Friedmann, O. Klineberg, R. Lefranc, R. Bonnardel, R. Meili, E. Souriau, P. Francastel, H. GratiotAlphandery and $H$. Dieuzeide.

Not the least important filmological experiments reported during the Congress were those to do with modifications of the electro-encephalograph during cinematograph projection. These experiments have been carried out in France by J. Bert, G. Cohen-Séat, J. Faure, H. Gastaut, G. Heuyer, S. Lebovici, Mme. Rebeillard, Mlle. Daveau, and others, and some of the experiments have already been reported in an issue of the official journal of the Institut de Filmologie, Revue internationale de Filmologie (January-March, 1954). Sound films containing news-reel type items have been used, and into these films have been infrequently inserted strips of film which leave the screen suddenly lighted but blank for a short period. In one experiment a 'western' adventure film and a film of strong emotional content-showing delinquents-have been used. The subjects of the experiments have been various, and in one experiment have included animal subjects (dogs). The effect on the electro-encephalograph of the fluctuation of light intensity during projection, isolated from the effect of representation, has been examined; and breathing and other physiological effects have been recorded.

Present knowledge is insufficient to permit defined interpretations of the electro-encephalograph. There were factors apart from those to do with the film projection which may have caused some of the observed modulations, and the experimenters them. selves do not claim to have arrived at sure conclusions. Nevertheless, these experiments represent pioneering work of a kind that may eventually lead to important advances in knowledge not only of the effects of film projection, but also in electro-encephalograph techniques and in the study of the brain. The film provides the research worker in this field with a convenient instrument. It may be that at length the film will provide the research worker in his laboratory with the means of presenting actual-life situations to the subjects of his experiments, and of studying the effects produced by such situations. First, however, it has to be established that reactions and thought processes similar to those that occur in ordinary life (when not watching films) can be brought about by film representation, and by what kind of film method. In relation to this, C. Denis Pegge maintained that there are two fundamentally different modes of mental reception from films, depending particularly on the use or non-use of speech; and he suggested that electro-encephalographic experiments might profitably be carried out to test this hypothesis.
A criticism made at the Congress of the electroencephalographic experiments so far accomplished was that some of the observed effects might have resulted from forms of representation other than that of the film; also, the primary need of establishing a classification of spectator reactions was discussed.

The object of this Congress, as of all international congresses - to make known what is being done in different countries-was admirably fulfilled, and not the least of its benefits were the personal contacts it allowed. Much of the material of its communications must probably remain unco-ordinated; but some clarification as to the best way of sub-dividing the large subject of filmology may well follow the arranging of the material for publication. This considerable task is now being tackled by the Congress Committee, and should result in an important book. Thanks are due to those who organized the Congress, including the general and administrative secretaries, Mme. Bianka Zazzo and Mme. Chantal Loiseau ; these latter were responsible for detailed arrangements which contributed to making this Congress not only valuable, but also most enjoyable.

C. Denis Pegae

\section{COMMONWEALTH FUND, NEW YORK}

\section{REPORT FOR THE YEAR 1953-54}

$T$

THE thirty-sixth annual report of the Commonwealth Fund, which covers the year ended June $30,1954^{*}$, lists more than forty appropriations made during 1953-54. Of the nineteen appropriations for medical education, thirteen were new grants. These grants fall into six general groups : those aimed at encouraging the better integration of professional and school or college education; those to assist the integrated teaching of the basic sciences to medical students in their first and second years; those to develop broader and more satisfactory relationships with patients by encouraging integrated teaching in the clinical years of the medical curriculum and better relations between the outpatient department, home cure and the community; those in mental health, where the integration of psychiatry and clinical medicine is being encouraged, and the Fund is this year assisting a programme in preventive psychiatry, both teaching and research; those in nursing activities, chiefly to clarify the place of nursing in health activities and the training required for it ; and those concerned with educational research and evaluation. The last, it is hoped, will lead to the development of improved techniques for assessing particular accomplishments or changes in students, better methods of selecting students for admission to medical schools, and the better definition and clarification of the objectives of the medical faculties themselves, as well as the provision of factual information as a basis both of administrative decisions and of the judgments that students are called upon to make about their future careers.

Five grants were made for experimental health services, the largest being a three-year grant to the Mary Imogene Bassett Hospital, Cooperstown, New York, towards the provision of a psychiatric service for a scattered rural constituency. Another was

* Commonwealth Fund. Thirty-sixth Annual Report for the Year ending June 30, 1954. Pp. ix +42. (Commonwealth Fund, 1 East 75th Street, New York, 1954.) 